\title{
Training Students' Practical Innovation Ability,by Building a Four Level Discipline Competition Platform
}

\author{
Cao Pan ${ }^{1, \text { a }}$, Hui Ding ${ }^{2, \text { b }}$, Hongfei Liu ${ }^{1, c}$ \\ ${ }^{1}$ Huaide College, Changzhou University, Changzhou,213164, China \\ ${ }^{2}$ School of Information Science and Engineering, Changzhou University, Changzhou,213164, China \\ aemail:pccczu@cczu.edu.cn, bemail:dinghui1213@cczu.edu.cn, email:1339691400@qq.com
}

Keywords: Discipline Competition;Innovation Ability;Incentive Mechanism

\begin{abstract}
Discipline competition has become an important part of colleges and universities talent training.It has a positive role to cultivate students' innovative practice ability and team cooperation ability.This paper proposed the building of four levels discipline competition platform system(school, city, province, country) and discussed the support system of the competition.
\end{abstract}

\section{Introduction}

Discipline competition is closely integrated in class teaching or the application of new technologies.It uses the methods of contest to cultivate students' comprehensive ability of the competition, and guides students to discover and solve problems, strengthen students' initiative of study and research,cultivate the students' team cooperation consciousness and innovation spirit by completing competition tasks.

With the continuous development of science and technology, enterprises are increasingly demanding on college students' innovative practice ability.In order to make college students to integrate into society as early as possible, universities should be free from the traditional model of single teaching theory knowledge, pay more attention to cultivate the students' practical innovation ability with new pattern.To develop different levels of discipline competition is the effective method to adapt to this pattern.In January 2007, the Ministry of Education, Ministry of Finance jointly issued the comment about the implementation of the higher school undergraduate teaching quality and teaching reform project. clearly put forward: "continue to carry out college students' competition,key funding in the students contest country which has a greater impact and a wide range of participation,to stimulate students interest and potential,to cultivate the sense of teamwork and innovation."among the quality construction content[1].

\section{The Role and Significance of Carrying out the Discipline Contest in Universities}

Discipline contest has become a major form of Practical Teaching in Colleges which is an important part of universities talent training goals, through discipline competition can stimulate students' interest in learning, train students' practical ability, cultivate the students' team cooperation spirit, and enhance the students' study enthusiasm[2].

A. Through high-level discipline contest promote the enhancement of students' creative ability and practical ability.

The contest topic or programs have some practical significance, more integrated, so it has the high requirements to participating students' comprehensive quality. The students requires not only comprehensive utilization learned knowledge, also need to put these knowledge extends in the process of competition.

B. Through the disciplines contests to cultivate the students' team cooperation spirit.

A lot of competition in the form of the team in the competition, which requires group members to division of labor and close cooperation to complete the competition process.. For example, in the "National Undergraduate Electronic Design Contest,a group of three students to finish scheme, 
hardware, welding, software programming and system debugging, writing technical reports, such as many tasks in 4 days and 3 nights, this is the group classmate has the good team spirit, rational division of labor, mutual cooperation, can successfully accomplish competition task.

\section{Through discipline contest to promote the reform of teaching content.}

The content of Competition sponsored by the education department and the various industries subject closely linked to the current teaching content, which is the combination of theory and practice,the combination of design and production , the combination of a subject knowledge and multidisciplinary,also is special attention to the application of new technologies, new devices, new instrument, and this plays a positive role in promoting educational reform, especially in the reform of practice teaching.

\section{Through the discipline competition strengthens students' employment competitiveness.}

At present, our country has entered the era of mass higher education, college students employment faces unprecedented competition and challenge. For example the most famous IT enterprises in the recruitment of graduates are particularly favor those who participate in high level competitions during the period of school.

\section{Construction of Four Level Discipline Competition Platform}

College students' multidisciplinary competition platform is an integrated system,which provides a variety of resources for college students to participate in all kinds of disciplines.Its goal is to get more competition results, maximize guiding role of the competition, mainly includes the competition organization,competition training,resource integration,etc.

Build school, city, province, country four levels of discipline competition platform, to stimulate students' interest in learning, improve the innovative ability of students, mobilize students' learning enthusiasm,and guiding and encouraging the students to the knowledge accumulation, boldly applied in practice.At the same time,through the different levels of competition activities to let students enhance confidence, improve competition consciousness, strengthen the team cooperation[3][4][5].Four level discipline competition platform system is as follows:

\section{A. School Level}

Colleges and universities organized discipline contest by themselves. The various discipline contests are variety, low difficulty, various forms and students' nationality.For example, in computer science, changzhou university hold a series of software technology series in the first half of each year ,including program design, Flash animation, three-dimensional animation, graphic design four themes,and hold the electronic information contest in the second half of each year, including computer assembly, electronic system design, control system design, three themes.

\section{B. City Level}

Discipline competitions are organized by the university in city. Such as the animation contest every year in changzhou city.

\section{Province Level}

Discipline competitions are organized by the university in the province or region.Such as provincial college students electronic design contest, provincial collegiate programming contest, provincial college students' information security competition, etc.

\section{Nation level}

Discipline competitions are organized by the national ministries and the national association of college related academic steering committee, discipline groups.Such as the national undergraduate electronic design contest, the national three-dimensional digital innovation design competition, "challenge cup" national college students' science and technology works competition, "freescale" cup national smart car competition, the national contest of software design and development professionals, etc. 
School and city level discipline competition focuses on examining students' basic skills, province level focuses on examining students' comprehensive ability and nation level competition focuses on the innovation ability as shown in Figure1.By building a four level discipline competition platform, schools can achieve point to an area to jointly improve the culture method.For example in order to be able to send out the best talent to participate in the national college student electronic competition, the school organized the campus electronic design competition, first entry personnel selection, and then focus on training, and actively prepare for the national electronic design contest at the provincial level.

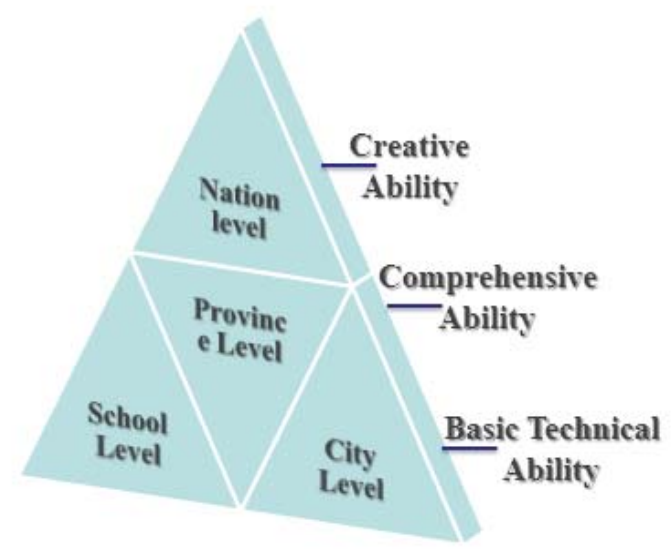

Fig.1. A four level discipline competition platform

\section{Support of Discipline Contests}

\section{A. Improve the organization and management of normative systems}

Office of Academic Affairs is discipline competition management, audits files all kinds of competition, determines the competition enforcement unit;Responsible for contact with competition authorities coordination work.To be responsible for the students and teachers award grades of examination and approval.To be responsible for the students and teachers award grades of examination and approval. College leaders are responsible for the implementation of Competition projects, including publicity, organization, registration and entry work, provide equipment, instruments, materials and space for competition.Equipped with necessary guidance teachers for student to race before the coaching and training, and guide students to participate in the competition[6][7].

For example,our university sets up a "Changzhou university students extra-curricular innovation fund",to encourage and support the college students to participate in scientific and technological innovation activities.It allocates special funds to help the students to research the science and technology innovation projects; guides students to actively participate in various innovation contest; awards the winning students and teachers in all kinds of innovation competitions.

\section{B. Establish high professional quality of teachers}

The key of training practice innovative talents is to pay attention to cultivate students ability to solve practical problems, and the traditional classroom teaching, usually adopts the mode of the teacher speak and students listen.In order to develop the students' ability of this kind of innovation, you need to stretch the limited class time to the extra-curricular or the second classroom. The extension of the class time is not only requires teachers to have strong business ability, also need teachers have strong sense of responsibility and dedication.Therefore colleges and universities need to equipped with a high comprehensive quality, strong business ability of teachers, on the one hand, can be arranged with $\mathrm{PhD}$ teachers to participate in the first line of the teaching activity, on the other hand can also employ some engineers who have the very strong practical experience and skills from enterprise as students competition training guidance teachers, to do both to ensure the number of teachers, but also to ensure the quality of teachers.

\section{Build effective incentive mechanism}

In order to arouse the enthusiasm of the masses of teachers and students to participate in the discipline competition, to build a good atmosphere of competition, universities should establish an effective incentive mechanism.Award-winning teachers and students should be encouraged, and in 
accordance with the level of the competition, the influence and competition winning situation, universities should offer a certain amount of training fees to the participating teams.

\section{Build an open laboratory environment}

The laboratory is the cradle of cultivating innovative talents, strengthen laboratory building is a necessary condition for the students to engage in academic competition and technological innovation activities. With the regular activities of scientific and technological innovation, the continuous improvement of the scale and degree of specialization, the basic conditions of the hardware options and equipment is also improving. Colleges and universities should strengthen laboratory building efforts,increase scientific and technological innovation funds, provide more innovation experimental base or laboratory teaching resources, to meet the needs of scientific and technological innovation activities,encourage students to bring their own issues into the open innovation laboratory to experiment, to encourage them to innovate,and practice[8][9][10].

\section{Conclusion}

The discipline competition is becoming more and more important.Colleges and universities should gradually form a new innovative ability training mode, it will be based on the students' innovation base as the center, relying on the four level discipline competition platform, it plays an important role to improve the quality of personnel training.

\section{References}

[1] Yin Jinrong, Luo Feng, Wang Dong.Thinking of College Students' Creativity link[J] Chinese Adult Education, 2007 (3): 49-50.

[2] Li Juan, Liu Jie. The discussion about management and operation pattern of university discipline competitions [J] Journal of education and profession, 2012 (5) :149-150.

[3] Zhu Changping, Huang Bo, Zhu Chensong, Through the "three-level experiment" to culture the electronic information students' innovative ability [J].Research and Exploration in Laboratory, 2007, 26 (7): 5-8.

[4] Liu Changhong, Xiang-Yang Qi, Xue Meng, Wang Gang, Zhang Hengqing The reform research and practice about Four levels and three dimension discipline competition system[J].Research and Exploration in Laboratory ,2011,30 (1) :109-111.

[5] Jiang Ximing, Deng Ming, Xu Yun Build the discipline competition system, and improve the students' comprehensive quality[J].Experimental Technology and Management, 2005,25 (2) :130-132.

[6] Xu Hui,Yu Hanqi ,Cu Nanfeng.Depending on the Cooperative PIatfOrm of College and Enterprise to Heighten the Undergraduate'S Discipline Competition Level[J].Research and Exploration in Laboratory,2010,29(12):153-155

[7] Yin Shi,Xiao Kan.Construction of multidisciplinary competition platform for cultivation of new type of top-notch talents.Experimental Technology and Management.2009,26(5):121-124

[8] Li Jinchang,Lin Jialian.Promoting the cultivation of innovative talents through combination of practical teaching and academic competition[J].Experimental Technology and Management. 2011, 28(11):1-4

[9] Sun Dun,Yao Yingying. Practice and Thinking of the creation of independent experiments. Experimental Technology and Management.2009,26(5):21-23

[10] Jiang Xuejun,Sui Yonghong.Reform of experimental teaching and students' innovative ability[J].Experiment Science and Technology.2006,4(2):79-81 